$12-29-2017$

\title{
Communities' initiatives in addressing hunger in relocation sites in Cebu, Philippines
}

Anecito Anuada

College of Agriculture and Food Science, University of the Philippines Los Baños, amanuada@up.edu.ph

Carla Melodillar

College of Agriculture and Food Science, University of the Philippines Los Baños

Follow this and additional works at: https://scholarhub.ui.ac.id/ajce

Part of the Social and Behavioral Sciences Commons

\section{Recommended Citation}

Anuada, Anecito and Melodillar, Carla (2017). Communities' initiatives in addressing hunger in relocation sites in Cebu, Philippines. ASEAN Journal of Community Engagement, 1(2).

Available at: https://doi.org/10.7454/ajce.v1i2.86

Creative Commons License

(c) (i) (2)

This work is licensed under a Creative Commons Attribution-Share Alike 4.0 License.

This Research Article is brought to you for free and open access by the Universitas Indonesia at ASEAN Journal of Community Engagement. It has been accepted for inclusion in ASEAN Journal of Community Engagement. 


\title{
Communities' Initiative in Addressing Hunger in Relocation Sites in Cebu, Philippines
}

\author{
Anecito Anuada ${ }^{*}$, Carla Melodillara \\ ${ }^{a}$ Agricultural Systems Institute, College of Agriculture and Food Science, University of the Philippines Los Baños
}

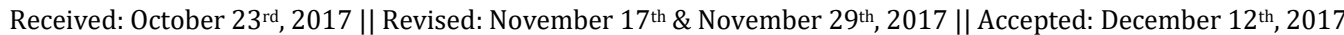

\begin{abstract}
Two villages in Cebu City, represented by 22 farmer-scientists, chose to conduct the third phase of their Urban Vegetable-Gardening Project in two relocation sites in the municipality of Bogo City to help displaced fisher folks affected by Typhoon Haiyan in 2013. The study aimed to determine the results of the project in addressing the eminent hunger in the relocation sites; and discuss the effects of communities' initiatives in assisting fellow communities. The operation of the project emphasized collaboration between institutions and communities' involvement in decision-making and activities - all boils down to community engagement (Attree et al., 2011; Holland and Ramaley, 2008). The study was conducted in SM and Yolanda relocation sites in Bogo City from January to July 2016. Thirty randomly selected farmer-participants were interviewed using pre-tested and validated questionnaires. Key informant interviews, focus group discussions and secondary data gathering were also conducted. The project results noted were: 1 ) immediate food sources, especially in urban areas like the two relocation sites where there is limited space to plant; 2) increased in yield and income based on farmers' records; and 3) improved social capital (building trust, knowledge sharing and provision of assistance) among farmers, local government units and universities brought by communities' involvement in project implementation. It is therefore concluded that vegetable-gardening in the relocations sites could provide immediate food and income sources consistent with previous studies (Ozawa, 2010; PCCAARD, 2007). Further, community's engagement in extension projects facilitates not only technology and knowledge dissemination but also social capital and community networks and linkages, also consistent with previous studies (Ozawa, 2010). Based on the positive outcomes recognized, the project is recommended for expansion to other urban areas in Cebu province.
\end{abstract}

Keywords: community engagement; farmer-scientists; technology transfer; university-community linkage; urban vegetable gardening

\section{Introduction}

In 2013, the super typhoon Haiyan hit the Philippines. Many lives were lost, along with livelihood and physical assets. Aside from the wreckage, survivors of the disaster suffered from hunger due to food shortage. The University of the Philippines Los Baños (UPLB) through the Farmer-Scientist Training Program (FSTP) extended its services to the public by implementing the Urban Vegetable-Gardening Project in the villages of Luz and Lahug in Cebu City in 2014 (Urban Vegetable-Gardening Project Annual Reports, 2014-2016). FSTP is the banner extension program of UPLB; a multi-awarded program operating for more than 20 years. The program is composed of staff with various fields of specialization such as Agricultural Economics, Agronomy, Community Development, Development Communication, Development Management, Entomology, Extension Education, Forestry, Plant Pathology, and Soil Science. FSTP was conceptualized in 1994 to address hunger issues in Cebu and focused on increasing corn production for consumption and market, as well as integrating other crops and livestock to optimize agricultural productivity (Melodillar et al., 2016). From being corn-based, FSTP was modified to become vegetable-based and was first implemented in Luz and Lahug urban villages to improve vegetable production for consumption through urban gardening. The first set of participants underwent three phases, and during Phase III, they chose 
SM and Yolanda relocation sites in Bogo City as beneficiaries to help the affected fisher folks.

The relocation sites were established to provide shelter to displaced fisher folks due to typhoon Haiyan. It was put up in an available space with funds from the local government and private institutions. Due to the far location of the fisher folks' relocation sites from the sea, their limited knowledge in farming, and dependency on scarcely available relief goods hunger began to strike in the relocation sites (Urban Vegetable-Gardening Project Annual Reports, 2014-2016).

As urban agriculture was documented to have many benefits for both the gardener and the whole community, particularly the immediate production of food despite the limited space to plant (Ozawa, 2010), the Urban Vegetable-Gardening Project was extended to the relocation sites to address food shortage in the areas. However, since the vegetable-based FSTP was a new approach, there was no study on how effective it was going to be in promoting household-level food sufficiency. Further, there were also no formal studies on the outcomes of community-to-community extension approach relevant to FSTP implementation. The result of the study is significant regarding improvement in the project implementation strategies, continuation and expansion of the project, and contribution to existing research on community engagement.

The study was conducted from January to July 2016 in Bogo City to determine the results of the project in addressing the eminent hunger in the relocation sites, and discuss the effects of communities' initiatives in assisting fellow communities.

\section{Theoretical Background}

\subsection{Community Engagement}

Holland and Ramaley (2008) defined community engagement as:

"Community Engagement describes the collaboration between institutions of higher education and their larger communities for the mutually beneficial exchange of knowledge and resources in a context of partnership and reciprocity" (Carnegie 2006).

The term was further associated with community participation which entails active involvement of community members towards collective decision-making (Sarkissian et al. 2009; Attree et al. 2011). From the collaboration of stakeholders to "collective" thinking of communities, community engagement was later defined in a broader context which including working with identified groups, regardless of social, cultural or geographical classifications, towards achieving a common objective. This is a key strategy encompassing diversity in communities leading to inclusive community development (Moore et al. 2016).

The study revolved around these definitions, emphasizing how a community contributes to the improvement of another community of which the composition regarding livelihood, geographic location and environment, is different from the latter. Furthermore, the study highlighted the importance of university-community linkage towards enhanced community engagement as defined earlier.

\subsection{Urban Gardening}

Ozawa (2010) stated that urban gardening started in 1890 to 1930 with purposes changing over time - from beautifying the surroundings to growing food to support families. It was defined as farming in the city and other highly urbanized areas with 
limited space to plant (Duldulao, 2001) and was also considered as a strategy to reduce food insecurity, poverty and environmental problems (USDA Alternative Farming System Information Center). Further, it provides opportunities to supply the residents with fresh food, create jobs, generate income, and may enhance environmental management (PCAARRD, 2007).

In the Philippines, according to Nitural (n.d.), urban gardening (also termed as urban agriculture) has been promoted and practised since the 1990s. In 1998, urban agriculture formally became a national program under the Department of Agriculture (Nitural, n.d.). A bill (House Bill No.: 720) on urban agriculture was also proposed in 2013. However, it was not passed into law yet. At present, urban agriculture programs and projects are being pursued by the different government and non-government institutions all over the country (Yanga, 2014).

\subsection{The Farmer-Scientists Training Program and the Urban Vegetable-Gardening Project}

The Farmer-Scientists Training Program (FSTP) is a corn-based, integrative and holistic three-phased agricultural research, development and extension program implemented by the College of Agriculture and Food Science of the University of the Philippines Los Baños. It aimed to improve farmers' income and quality of life beyond poverty level through a partnership with different government and non-government agencies concerned with poverty reduction among farmers and the country's food security program. It presently covers 121 municipalities throughout the Philippines (Velasco, 2016).

The three phases involved Values Formation, Research Exposure and Technical Empowerment (Phase I), On-farm Technology Verification and Adoption (Phase II), and Farmer-to-Farmer Technology Transfer (Phase III). After Phase III, FSTP will operate in a smaller context and on a specific community. A graduation program is being conducted after every Phase; and a Farmer-Scientists Association will be formed and registered at the end of Phase I municipal level (Figure 1) (FSTP Manual of Operations, 2009; Melodillar et al. 2016). It uses technology transfer approach, on-farm experimentation, farmer-to-farmer extension approach and facilitation towards empowerment at the individual and community levels.

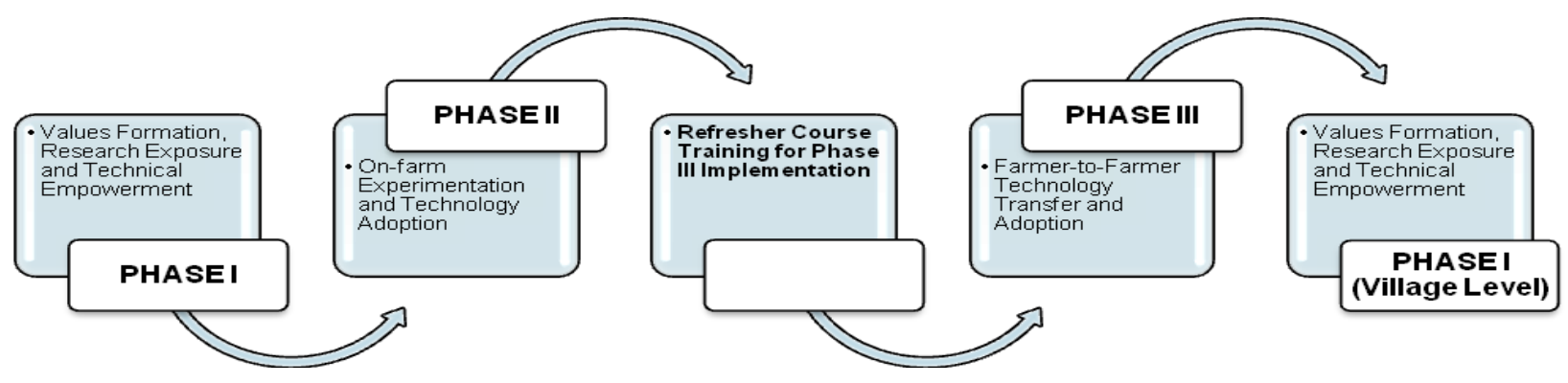

Fg. 1 Framework for Implementation of FSTP Source: Melodillar, et al., 2016

For over 20 years of operation, FSTP has produced some success stories which include discoveries of farmer-scientists that became a formal research study, improvement of agricultural production and income of farmer-scientists, and formation of local scientific and economic coalitions towards the advancement of the community (Melodillar et al., 2016). 
Using the concept of FSTP, which promotes scientific farming by experimentation to help farmers make decisions for their farms, modules and experimental trials on vegetable production in urban areas were developed and implemented. In this project, the farmer-participants will have direct contact with the experts from various institutions in conducting their experimental trials which include Fertilizer Trial, Integrated Pest Management Trial and Method of Planting Trial. On the other hand, the experts will also have access to on-farm resources to test and improve the technologies they develop (Urban Vegetable-Gardening Project Manual of Operations and Management, 2014).

The first batch of training was held in Cebu City which produced 26 farmer-scientists from July 2014 to May 2015. They attended weekly classes, tackled lectures on various vegetable productions, and formed an association. The same set of farmer-scientists continued to Phase II from June to October 2015 wherein they established their experimental trials in their backyards to observe the differences of each treatment, and finally decide which one is suited for them. Only 22 of them could finish Phase II and continued to Phase III in which they were required to teach their fellow farmers through adopt-a-farmer or adopt-a-village scheme. In this case, they opted for the adopt-a-village scheme and chose to teach the evacuees in the two relocation sites in Bogo City named SM and Yolanda sites. The farmer-scientists from Luz and Lahug villages were the main facilitators of the project in the relocation sites, who conducted weekly classes on urban gardening and helped the establishment of experimental trials of the participants. FSTP staffs were involved in planning, monitoring of weekly activities and evaluation of project outcomes which includes the ability to produce vegetables for consumption and to sell surplus and earn income to address their other needs.

On the other hand, the partner-agencies helped in the implementation by providing inputs, assisting the farmer associations, conducting lectures and monitoring the project. FSTP staffs visited, monitored and evaluated the progress of the relocation sites from the beginning until it was finished. The whole Phase III was implemented from October 2015 to March 2016 and benefited 40 fisherfolks (Urban Vegetable-Gardening Project Reports 2014-2016).

\section{Methods}

\subsection{Study Sites}

The study was conducted in SM and Yolanda relocation sites in Bogo City, Cebu, Philippines. These were developed with the assistance of private and government institutions to help the survivors of typhoon Haiyan whose houses were destroyed (Figures 2 and 3). 


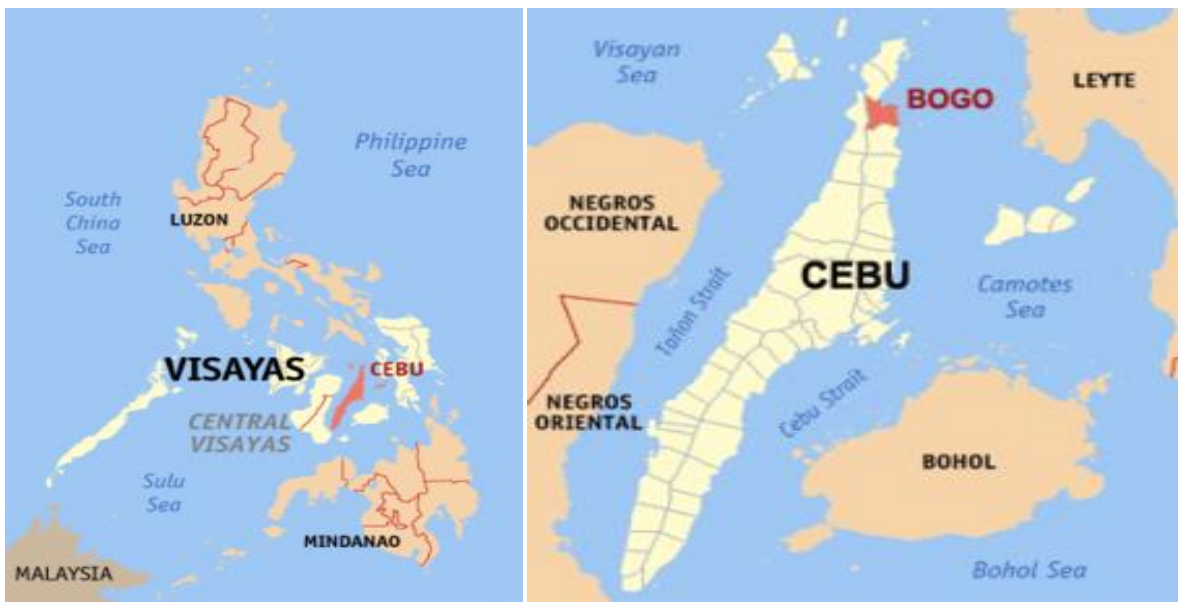

Fg. 2 Location of study sites. (Images downloaded from Google.com)
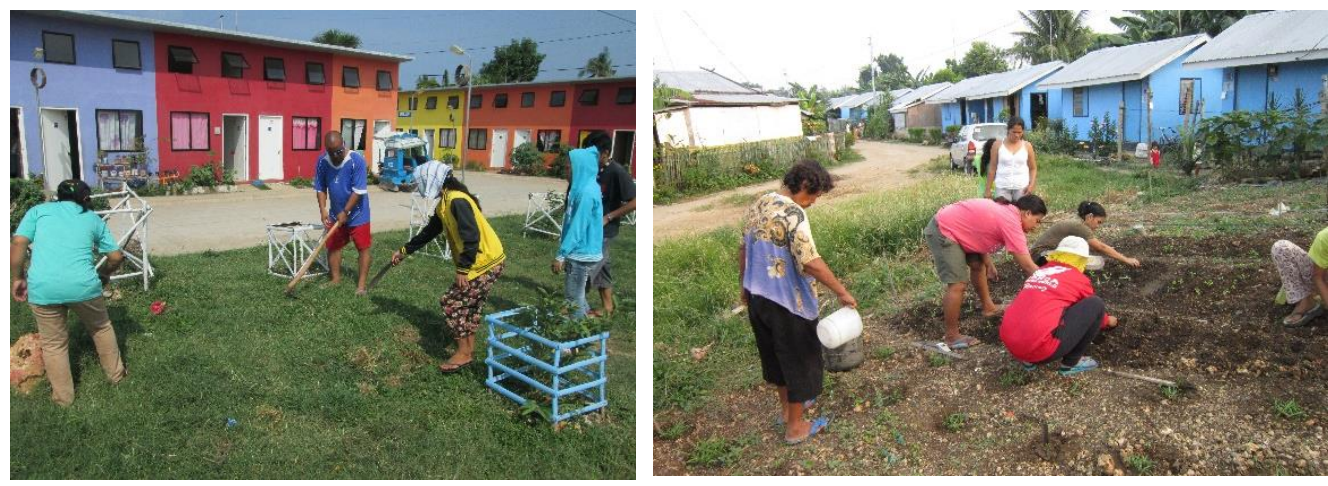

Fg. 3 The SM relocation site (left) and Yolanda relocation site (right) with the participants doing land clearing and maintenance of their experimental trials. (Photos were taken by AM Anuada, November 2015)

\subsection{Respondents}

Due to the small population, respondents of the study were 30 randomly selected participants using Fish-bowl method $(\mathrm{N}=40)$. In this method, a number was assigned to each participant in the list, and these numbers were all put inside a box. Respondents were identified by drawing a number from the box until a total of 30 respondents were drawn. The respondents were originally fisher folks who were relocated after being heavily affected by the typhoon in 2013.

\subsection{Data Gathering and Analysis}

The FSTP staffs visited weekly classes, conducted group discussions and inspected experimental trials as part of the project monitoring and evaluation activities. To properly and formally retrieve data for this study, key informant interviews and focus group discussions were conducted with the village heads, farmer-scientists and representatives of relocation sites from January to March 2016. This was done to verify their perception of the program and cross-check their observations with that of the FSTP staffs. Further, it aimed to strengthen findings on the improvement of social capital and importance of collaboration towards community development.

On the other hand, a survey questionnaire was structured to obtain data on sociodemographic, which was used in describing the respondents; and socio-economic data, 
which was used to determine if there was an increase in yield and income. Further, a questionnaire focusing on social capital was adopted from Krishna and Shrader (1999) and used to determine the improvement of social capital and further support findings obtained from key informant interviews and focus group discussions. The survey was conducted from April to June 2016 during which observations were done through monitoring and evaluation activities of the team. Follow-up and verification were done in July 2016.

The survey questionnaire for the socio-demographic and socio-economic data was pretested on 12 farmer-scientists before actual data gathering. Further, the results of the socio-economic data were confirmed using the farm records kept by the respondents. The data gathered were subjected to descriptive analysis such as measures of central tendency and variability.

\section{Results and Discussion}

The respondents $(n=30)$ are dominated by women $(90 \%)$, mostly married $(93 \%)$, with the average of 3 children per household, and aged 35 years on the average. Most of them finished high school (50\%), but some could attend vocational courses and collegelevel education (Table 1).

Table 1. Profile of the respondents

\begin{tabular}{|c|c|c|}
\hline Variables & Frequency $(n=30)$ & Percentage (\%) \\
\hline \multicolumn{3}{|l|}{ Gender } \\
\hline Male & 3 & 10 \\
\hline Female & 27 & 90 \\
\hline \multicolumn{3}{|l|}{ Civil Status } \\
\hline Single & 2 & 7 \\
\hline Married & 28 & 93 \\
\hline Widow/widower & 0 & 0 \\
\hline \multicolumn{3}{|l|}{ Educational Attainment } \\
\hline Elementary & 0 & 0 \\
\hline Secondary & 15 & 50 \\
\hline Vocational & 2 & 7 \\
\hline College undergraduate & 10 & 33 \\
\hline College graduate & 3 & 10 \\
\hline
\end{tabular}

Their temporary income is mainly from basket weaving, tailoring, and operating a small variety store or eatery in the relocation sites. However, the earnings from these livelihoods were irregular and seasonal as they depend on the bulk of job orders. While husbands earn income as construction workers, the wives usually have more time to attend training.

According to FAO (2011), women comprise about 43\% of global agricultural labour force especially in developing countries like the Philippines, and they were more burdened by unpaid household responsibilities and agricultural activities. FAO (2011) further emphasized that women's contribution to agricultural and food production is significant but cannot be detailed as agriculture is a family venture and involves a range of resources and inputs that cannot be classified by gender. However, this burden has been decreasing through time as the participation of women in agricultural and non- 
agricultural employment had been increasing (Ghosh and Ghosh, 2014; Lambrecht et al., 2017).

Akire et. al (2013) and IFPRI (2012) mentioned that indicators of women empowerment in agriculture include their decision power over crop and livestock production, access and use of land resources, control of income and expenditures; leadership in the community, and allocation of time to production and domestic tasks, and leisure activities leading to satisfaction. Although the study did not use the Women's Empowerment in Agriculture Index (WEIA) to measure the exact inclusion of women in the relocation sites as it was not included in the objectives of the study, the level of women involved in the project was manifested by their active and full participation in the activities such as attendance to weekly classes, data gathering and presentation, establishment of experimental trials, interpretation of experimental results and taking part in the associations.

\subsection{Documented Project Outcomes}

Immediate food source. One of the outcomes of the project based on the interviews conducted is that it provided an immediate source of food. Almost all the respondents were fisher folks before typhoon Haiyan occurred. Their only livelihood back then was fishing and selling it to local markets. Hence, they had little to almost no knowledge in farming. When they were affected by the typhoon and were relocated, the food source is their major problem. Through the project, step by step, they have learned how to grow vegetables of various kinds. Using recyclable materials like plastic bottles, sack, cups and other locally available containers, they started to grow their food for their families' consumption (Figure 4).

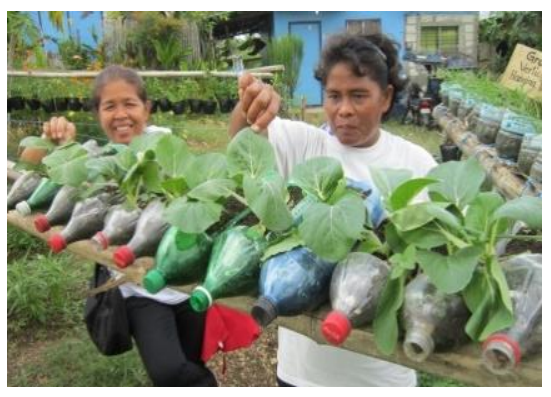

$4 a$

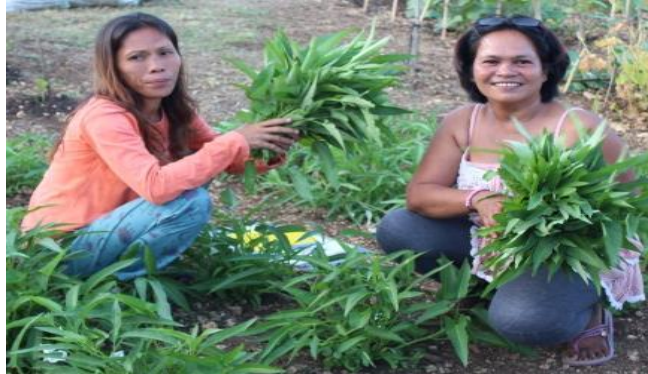

$4 b$

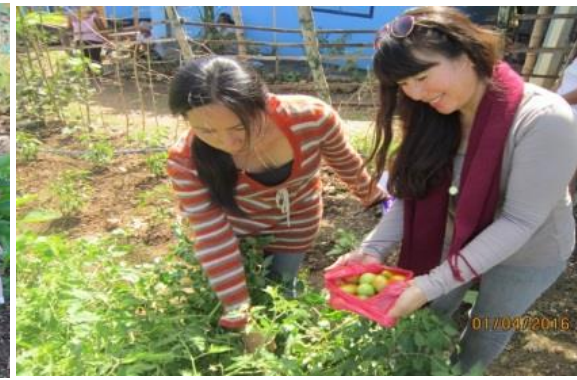

4c

Fg. $\quad$ 4a Participant Ms Milagros Brignas (right) and Farmer-Scientist Teacher Susana Service (left) inspect pests of Pechay (Brassica rapa L.) planted at the plastic coke bottles on vertical hanging trial.

4b. Participant Ms Rossel Ancero (right) together with her group mate harvested the Kangkong (Ipomoea aquatica Forssk.) on fertilizer trials.

4c. Participant Ms Herminia Arnoco (right) and Ms Filchin Valenzuela harvested the Tomato (Lycopersicon esculentum L.) on planting trial (direct seeding vs transplanting). Source: photo archive from Personal Pictures

The respondents further testified that by attending the project and learning to plant their food, they could eat and cook the fresh vegetables planted at their backyards immediately, thus, alleviating hunger at becoming food sufficient even at the household level. Consistent with the previous studies, the urban vegetable-gardening project indeed helped the farmer-participants become food sufficient even at the household level (Duldulao, 2001; USDA Alternative Farming System Information Center, 2000; and PCARRD, 2007). 
Increasing Yield and Income. Key informant interviews and focus group discussions revealed that aside from the food source, learning vegetable-gardening provided them additional income to sustain their families' other needs. Based on their farm's records, most of the respondents (63\%) in the relocation sites have increased their income, while $36 \%$ stated that their income remained the same.

However, all the respondents agreed that they do not buy vegetables for food in the market anymore as they produce their own, which further gave them opportunities to satisfy their other needs such as their children's education, acquisition of farm inputs and equipment and additional capital for operating their small enterprises. Thus, even if their income did not significantly increase, they became food sufficient at the household level. This finding is consistent with the findings of previous studies.

\subsection{Improved Social Capital Brought by Community Engagement}

According to Putnam (1995), "social capital is the potential in a social relationship that will enable members of the community to make collective decisions for achieving shared goals". Thus, aside from the tangible benefits, the respondents were also asked about their involvement in the community. The respondents stated that they have become more involved in the activities in their respective sites by participating in them. Moreover, since they are more organized and easier to facilitate, various government and non-government organizations are now coordinating with them, offering more livelihood training. All respondents declared that they are active and effective functioning in the associations formed in their respective sites. They have attended all the meetings, promptly paid the dues and participated in all its activities especially in promoting urban vegetable-gardening. In addition to that, all the respondents stated that they had learned new technologies and knowledge by sharing and interacting with their co-evacuees, as well as local government workers, especially when their crops were affected by an unknown cause, the assistance of local government became more accessible with the increased network formed through the associations. On the average, $77 \%$ of the respondents rated the spirit of participation as "high", while $23 \%$ of them rated it as "average".

When asked what the possible reasons for their participation were aside from the technical knowledge and material benefits, most of the respondents (93\%) stated that they wanted to have closer ties with their neighbours. According to the respondents, having closer ties with community members gave them a feeling of belongingness and importance as part of the community. They further stated that since they are all evacuees and relatively "new" in the area, the sense of belongingness is very important for them so they can work harmoniously together towards their communities' development. This finding is consistent with that of Clayton (2011) that one of the motivating factors for participation is the social benefits one can derive. This was further supported by the study of Kearney (2006) which stated that social satisfaction obtained from participation encompasses beyond the individual level.

The respondents further stated that from being indifferent - working individually to help themselves, they are now closer regarding trust, bonding and camaraderie. They work altogether to help one another by sharing their knowledge and encouraging other community members to participate in training as the project. They developed a sense of belongings and became a concern for the welfare of the community (Figure 5). 


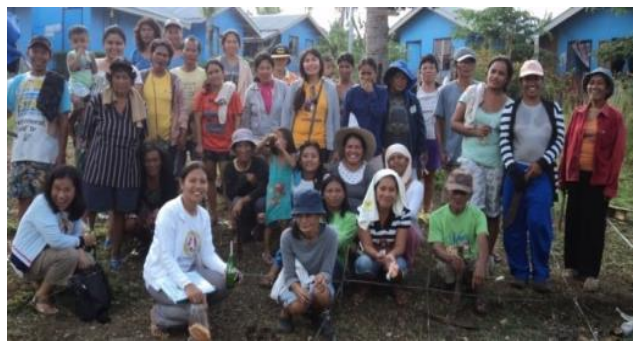

$5 a$

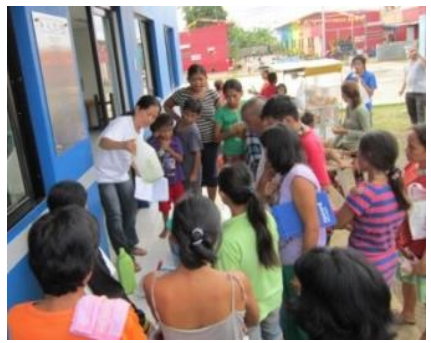

$5 \mathbf{b}$

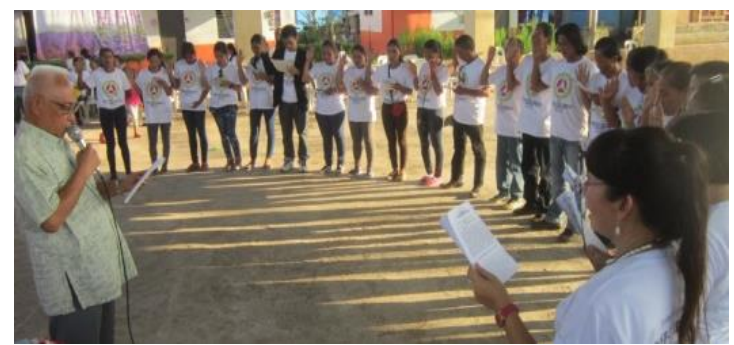

5c

Figure 5a. Group picture of participants together with the farmer-scientist teacher Lorena Soco ( $2^{\text {nd }}$ from the left sitting at the front) and Marilou Jumao-as (left setting at the front) during their weekly class.

5b. Farmer-Scientist Teacher Marilou Jumao-as demonstrates on making botanical insecticides.

5c. Dr Romulo G. Davide, FSTP Project Leader \& Professor Emeritus leads the Oath taking of Farmer-Scientists Officers during their graduation on last March 18, 2016.

Source: photo archive from Personal Pictures

The main target outcome of the project, which is household-level food sufficiency, had been met. The displaced fisher folks became food sufficient and could sustain their other needs by selling surplus from vegetable production. The FSTP and the farmerscientists from villages Luz and Lahug of Cebu City performed their role as a facilitator of the project to help the fisher folks overcome the hunger issues in the relocation sites. About community empowerment, as defined by Labonte and Laverack (2008), the fisher folks gained control over their access to food and ability to sustain their needs by actively participating in the project, which was catalyzed by external agents (FSTPUPLB and Luz and Lahug communities). The fisher folks were not empowered by external agents; they empowered themselves by acquiring strength in different forms such as technical knowledge, access to farm inputs and materials, and a decision over factors that affects their daily lives. Thus, from depending only on relief goods and irregular income, they become food producers themselves.

Furthermore, the community-to-community intervention done significantly contributed to the attainment of the project goal. About the Community Empowerment Theory (Hildebrandt and Persily, 2008), the farmer-scientists served as lay-workers. Regardless of the villages, they came from; they were all affected by the same calamity. This fact was a common denominator to both the farmer-scientists and the fisher folks and served as a factor for connecting, cooperating, organizing and influencing each other to work hard towards improving one's lives. Although empowerment is a process (Baum, 2008), the fisher folks in the relocation sites have taken their first step towards a developed and empowered community.

However, some shortcomings and difficulties during the implementation of the project were faced by both the implementers and participants. The main problem encountered stated by the respondents was the late release of project funds. Thus, activities were re-scheduled. This further resulted in inappropriate timing for growing vegetable crops and resulted in damage experimental trials. Aside from this, decreasing attendance of participants as the training goes by was also observed. When asked why they were sometimes absent, male respondents stated that they needed to attend other income-generating activities (such as daily labour) to be able to provide for their families' daily needs. Women respondents, on the other hand, had to attend to children's needs, especially school-related activities, and meetings with other non-government organizations where they were also beneficiaries. The said problems were solved by the 
farmer-scientists themselves by doing re-planting or re-establishment of experimental trials even if it took them longer time in conducting the training. In the case of decreasing attendance, the facilitators conducted make-up classes, and the group members took turns on maintaining the gardens and data gathering on their designated experimental trials (Urban Vegetable-gardening Project reports 2014-2016; recorded interviews; and actual observations).

Although the farmer-scientists could adjust to the said circumstances, the study suggested that project goals could have been attained as scheduled; and incurring additional inputs for re-planting or re-establishment of trials could have been avoided when funds were released on-time. Further, the provision of incentives to increase participants' motivation to attend and be involved in the training was encouraged. Aside from contributing to studies showing benefits of urban gardening in food production and income generation, the study emphasized the importance of community engagement and empowerment towards recovery from the post-disaster aftermath. Also, collaboration and cooperation of universities, local government units and communities could work towards improving the quality of services delivered to target clients when each institution would play their part, responsively attending to the needs identified, and implement projects in an inclusive manner so that no one will be left behind.

\section{Conclusions}

Based on the results gathered, it is concluded that the urban vegetable-gardening project in Bogo City has been effective in helping the fisher folks affected by typhoon Haiyan be food sufficient at the household level. It provided livelihood and source of income to former fisher folks who were relocated to a city. Furthermore, the participants developed a good relationship with other community members which helped them cope with an unfavourable condition. This is in line with the definition of community engagement as the initiative of a community to help their fellow communities which are affected by a natural disaster resulting in a more inclusive development as shown by the increased perception of belongingness, trust and selfesteem. Furthermore, evidence of women and community empowerment were observed as they eventually acquire the power to conquer hunger issues in the relocation sites by being involved, have access to, and decide over matters relevant to food production and livelihood. However, the study did not use inferential data analysis, and therefore, it cannot generalize the results of this case study in all other three areas where the project has been operated. At present, the project is recommended for the continuation and expansion to other areas in Cebu and Leyte provinces.

\section{Acknowledgement}

The authors would like to acknowledge the assistance of the local government of Bogo City, staff from Department of Science and Technology Region 7, and Dr RG Davide and staff of the Farmer-Scientists Training Program in UP Los Baños.

\section{References}

Akire, S., R. Meinzen-Dick, A. Peterman, A.R. Quisumbing, G. Seymour, \& A. Vaz (2013). The Women's Empowerment in Agriculture Index. World Development. 53. Pp 7191 
Anecito Anuada, Carla Melodillar | ASEAN Journal of Community Engagement | Volume 1, Number 2, 2017

Attree, P., B. French, B. Milton, S. Povall, M. Whitehead, \& J. Popay (2011). The experience of community engagement for individuals: a rapid review of evidence. Health \& Social Care in the Community, Volume 19(3), 250-260. doi: 10.1111/j.1365-2524.2010.00976.x

Available from http://dx.doi.org/10.1111/j.1365-2524.2010.00976.x

Baum, F. (2008) Foreword to Health promotion in action: from local to global empowerment. Accessed at www.who.int

Clayton, J. (2011). Living the multicultural city: acceptance, belonging and young identity in the city of Leicester, England. Journal on Ethnic and Racial Studies. Volume 35 (9). Retrieved at: http://www.tandfonline.com/doi/abs/10.1080/01419870.2011.605457

Duldalo, V.A. (2001) “Gulayan at bulaklakan: A component of the government's Urban Agriculture Program". Paper presented during the National Conference-Workshop on Urban Agricultural Systems in the Philippines, January 15-17, 2001, Bureau of Soils and Water Management, Quezon City.

FAO (2011). The role of women in agriculture. ESA Working Paper No. 11-02. Agricultural Development and Economics Division accessed at www.fao.org/economic/esa

FSTP Manual of Operations (2009). Agricultural Systems Cluster, College of Agriculture, University of the Philippines Los Banos (unpublished).

Ghosh, M.M. \& Ghosh, A. (2014). Analysis of women participation in Indian agriculture. IOSR Journal of Humanities and Social Science. Vol. 19 (5). Pp 1-6 ISSN 2279-0849 accessed at www.iosrjournals.org

Hildebrandt, E. \& Persily, C.A. (2008). The community empowerment theory. Springer Publishing, New York. Accessed at: www.springer.com

Holland, B., \& Ramaley, J. A. (2008). Creating a supportive environment for communityuniversity engagement: conceptual frameworks. Paper presented at the HERDSA 2008: Engaging Communities. Available from https://herdsa.org.au/publications/conference-proceedings/research-anddevelopment-higher-education-place-learning-and-62

International Food Policy Research Institute (2012). The Women's Empowerment in Agriculture Index accessed at www.ifpri.org

Kearney, A. R. (2006). Residential development patterns and neighborhood satisfaction: Impacts of density and nearby nature. SAGE Journals. Volume 38 (1). Pp 112-139. Retrieved at https://doi.org/10.117710013916505277607 
Krishna, A. and E. Shrader (1999). Social capital assessment tool. Paper presented at the Conference on Social Capital and Poverty Reduction. June 22-24, 1999. The World Bank. Washington D.C.

Labonte, R. \& Laverack, G. (2008). Health promotion in action: from local to global empowerment. Accessed at: www.who.int

Lambrecht, I, Schuster, M., Asare, S., \& Pelleriaux, L. (2017). Changing gender roles in agriculture? Evidence from 20 years of data in Ghana. IFPR Discussion Paper 01623. Washington DC: International Food Policy Research Institute, Development Strategy and Governance Division.

Melodillar, C.O., R.G. Davide and WS Velasco (2016). Towards liberation from poverty and hunger: the Corn-based Farmer-Scientists Research, Development and Extension Training Program (FSTP) for Sustainable Agricultural Development under E.0. 710. Journal of Perspectives on Development Policy in the Greater Mekong Region. Volume 4 (1). Chiang Rai Rajabaht University, Thailand. Retrieved at: http://icmr.cru.in.th

Moore, T., McDonald, M., McHugh-Dillon, H., \& West, S. (2016). Community engagement: A key strategy for improving outcomes for Australian families (Child Family Community Australia Paper No. 39). Melbourne: Australian Institute of Family Studies. Available from https://aifs.gov.au/cfca/sites/default/files/cfca39community-engagement.pdf

Nitural, P.S. (n.d.) Urban Agriculture Program in the Philippines: Its Beginnings and Status. $\quad$ Retrieved at: n.fftc.org.tw/htmlarea_file/activities/20110719103448/paper-947796964.pdf on June 23, 2016

Ozawa, Takuya. (2010). "Phenomenological study of urban vegetable gardening in Halifax: How does urban vegetable gardening activity affects the daily lives of the gardeners and their sense of community?". BS Thesis. Dalhousie University. Accessed at: www.dal.ca/content/dam/dalhousie/pdf/science/environmentalscience-program/Honours\%20theses/TakuyaOzawa.pdf

Philippine Council for Agriculture, Forestry and Natural Resources Research and Development. (2007) "Urban vegetable production in the Philippines". Los Baños, Laguna: PCARRD-DOST. 96p. - (Book Series No. 176/2007) ISBN 971-20-0535-0.

Putnam, R.D. (1995). Bowling Alone: The America's declining social capital. Journal of Democracy. Vol. 6 (199) 1. Pp 64-78. Retrieved at http://dlcdlib.indiana.edu/dlc/bitstream/handle/10535/7661/siisiairen.pdf

Sarkissian, W., Hofer, N., Shore, Y., Vajda, S., \& Wilkinson, C. (2009). Kitchen table sustainability: Practical recipes for community engagement with sustainability. London: Earthscan. 
Urban Vegetable-Gardening Project Annual Reports (2014 to 2016). Agricultural Systems Cluster, College of Agriculture, University of the Philippines Los Banos (unpublished).

USDA Alternative Farming System Information Center. Urban agriculture. An abbreviated list of references and resource guide, 2000. https://pubs.nal.usda.gov/sites/pubs.nal.usda.gov/files/urban_0.htm

Velasco, W.S. (2016). FSTP Background in FSTP Training Modules (unpublished). Agricultural Systems Institute, College of Agriculture, UP Los Banos, Laguna.

Yanga, B. (2014). Proposed Bill on Urban Agriculture Pushed. A Newsletter retrieved at http://ati.da.gov.ph/news/2014/proposed-bill-urban-agriculture-pushed on June 23, 2016 